Jan Celko - Matus Kovac - Kristina Huszarova

\title{
INFLUENCE OF SELECTED VEHICLE MANEUVERS ON REDUCTION OF THE URBAN ROADS CAPACITY
}

Capacity assessment of urban roads according to Slovak standard does not sufficiently take into account the influence of vehicle maneuvers on road section performance between the two intersections. This research analyzed turning relations on selected urban road intersections and the influence of right turn and left turn on major stream speed changes. For the purpose of determining the influence of the right turn on decrease in capacity, measurements were carried out at 7 uncontrolled intersections with curve radius ranging from 6 to $30 \mathrm{~m}$. To determine the influence of the left turn on the capacity of urban road a critical gap was evaluated, using the Raff's, method, based on the analysis of accepted and rejected gaps in the major traffic stream, which was one of the main inputs for simulations. The findings were used to determine the influence of selected maneuvers on the road capacity, which led to a proposal for reduction coefficients based on computational analysis performed using simulations in PTV VISSIM.

Keywords: traffic, urban roads, capacity, traffic flow, simulation

\section{Introduction}

Influence of the turning maneuvers at simple intersections and parking spaces on the reduction of the capacity of urban roads has not received much attention. Focus has predominantly been directed at signal intersections, e.g. Kim [1].

Several models and analyses were created for unsignalized intersections, which consider turning relations [2-6].

Authors of [7] dealt with an analysis and modelling of turning relations and their influence on the intersection capacity in urban intersections in China. They generally focused on two types of crossing behaviors. The first type is called the single-vehicle-crossing (SVC) and usually appears when the traffic flow is not saturated. The second type is known as vehicle-stream crossing (VSC) and refers to situations when one or more vehicles have to seek for the right gap to move across another vehicle stream. More attention from researchers is devoted to describing this type of crossing behavior.

Research has also focused on the capacity analysis of turning maneuvers on the U-turn intersections and their influence on the capacity of the intersections. This topic was addressed in [8] where analysis applied the values of the base critical gaps $t_{c \text {,base }}$, as well as the base follow-up time $t_{\text {f,base }}$.

The critical gap was determined to be about $6.4 \mathrm{~s}$, the follow-up time $2.5 \mathrm{~s}$. In the case of U-turns, accommodated at median openings with narrow median nose width of $6.4 \mathrm{~m}$, the critical gap was about $6.9 \mathrm{~s}$ and the follow-up time $3.1 \mathrm{~s}$. Difference in capacity was up to $286 \mathrm{pc} / \mathrm{h}$ for making the $\mathrm{U}$ turns at median openings with narrow medians (median nose width $6.4 \mathrm{~m}$ ).

The turning relations are often simulated by software tools. In recent years, VISSIM of PTV VISION packet has been used most frequently.

Researchers in [9] simulated the turning relations using the VISSIM. Although their analysis of turning was predominantly based on the Harder's model, they also determined the base critical gaps for different types of movement on unsignalized intersections (Table 1). Apart from presenting important data, the model confirms the suitability of the VISSIM program for similar purposes.

Delay during the turning relations on intersections is also analyzed in the Highway Capacity Manual [10]. The HCM analyzes the problem of calculation of delay during the turning on intersections separately for the left and right turns. The delay during the right turn is solely a result of deceleration of turning vehicles and the adaptation to the speed of previous vehicles. The delay during the left turn is a result of waiting for the previous vehicle to complete their turning maneuver. Generally, the typical values of delay given in Table 2 may be used.

The values are only valid for $10 \%$ of turning vehicles and must be reduced in the case of the remaining vehicles. Predictions of speed changes on the right turning lanes on urban streets are offered in [11].

The parking manoeuvers significantly contribute to reduction of the capacity of urban streets. Results of [12], which describe the number of lanes and the number of parking manoeuvers per hour as the variables for the capacity reduction, were adopted in the HCM 2000 [10]. Likewise, Valleley in [13] focuses on relation between

\footnotetext{
Jan Celko ${ }^{1, *}$, Matus Kovac ${ }^{1}$, Kristina Huszarova ${ }^{2}$

${ }^{1}$ Department of Highway Engineering. Faculty of Civil Engineering, University of Zilina, Slovakia

${ }^{2}$ Freelance researcher, Zemianske Kostolany, Slovakia

*E-mail of corresponding author: jan.celko@fstav.uniza.sk
} 
Table 1 Critical Headway and Follow-Up Time for Different Turning Movements, [9]

\begin{tabular}{lcc}
\hline Vehicle movement & $\begin{array}{c}\text { Base critical, } \\
\text { tc,base (s) }\end{array}$ & $\begin{array}{c}\text { Base follow-up time, tf,base } \\
(\mathrm{s})\end{array}$ \\
\hline Left turn from major (four-lane) & 4.1 & 2.2 \\
U-turn (six-lane) & 5.6 & 2.3 \\
U-turn (four-lane, wide median) & 6.4 \\
U-turn (four-lane, narrow median) & 6.9 \\
Through traffic on minor (four-lane) & 6.5 & 3.5 \\
Left turn from minor (four-lane) & 7.5 & 4.0 \\
\hline
\end{tabular}

Table 2 Typical values of delay by HCM [10]

\begin{tabular}{cccc}
\hline $\begin{array}{c}\text { Midsegment Volume } \\
(\mathrm{veh} / \mathrm{h} / \mathrm{ln})\end{array}$ & \multicolumn{2}{c}{ Through Vehicle Delay (s/veh/pt) by Number of Through Lanes } \\
\cline { 2 - 4 } 200 & 1 Lane & 2 Lanes & 3 Lanes \\
300 & 0.04 & 0.04 & 0.05 \\
400 & 0.08 & 0.15 & 0.09 \\
500 & 0.12 & 0.25 & 0.15 \\
600 & 0.18 & 0.41 & 0.15 \\
700 & 0.27 & 0.72 & 0.15 \\
\hline
\end{tabular}

the number of parking maneuvers and the reduction of urban road capacity. Yousif and Purnawan [14] analyze the difference in time delays between the parallel and angle on-street parking.

Authors of [15] analyze the influence of these changes on the travel-time delays. The parking maneuvers affect car and bike lanes. They also increase the delay of traffic and reduce the capacity of the adjacent travel lane. Along with that, on-street parking also increases the number of traffic accidents. They conclude that on-street parking could reduce capacity and cause congestion. Their model is designed to predict delay in the travel time during the parking maneuvers under various conditions.

The methodology of collection, selection and analysis of data regarding the characteristics of traffic flow and observations of actual intersections in the city of Zilina were performed as a part of research activities conducted at the author's institution. The aim of this part was to determinate the influence of selected maneuvers on urban road capacity. The analysis included the effect of turning vehicles to the capacity of the intersection without the influence of next effects, e.g. impact of pedestrians, in the sense of Slovak Standard for the simple intersections. Only the analysis of regular intersections was selected for presentation in the paper.

The results were compared to the currently effective methodology stated in Slovak standard, which only takes into consideration the influence of maneuvers that is based on their minimum numbers. To verify the theoretical calculations, measurements were used as input into a simulation model which was used to further specify obtained results.

\section{The influence of turning vehicles on the capacity of urban roads}

\subsection{Right turns}

Measuring spots were selected based on the previous research findings related to the characteristics of traffic and road network, in a way that would represent maximum range of radius sizes for turns from the main road, a sufficient number of turns with respect to traffic intensity and the angle of intersection of approx. $90^{\circ}$. Altogether, 7 uncontrolled level intersections with curve radius ranging from 6 to $30 \mathrm{~m}$ were tested. Measurements were carried out at individual spots in duration of 4 hours in order to record the traffic flow during the peak hour, as well as in lower volumes.

Instantaneous vehicle speed during the right turn was measured using a hand-held radar. Measured and analyzed were factors, as well as deceleration of vehicles, prior to turning with respect to the curve radius.

In order to determine a generally valid dependency, the data were selected at two levels and the resulting sample was used to determine the level of influence of the right-turn maneuver on the urban road capacity. To assure objectivity of both selections, the data were processed according to the standards of mathematical statistics and the speed dependency on turn and radius size was determined, as illustrated in Figure 1.

Results show quite a wide range of speeds on turns. While the speed on a turn of $\mathrm{R}=6 \mathrm{~m}$ is in the range of $20.59 \pm 2.89 \mathrm{~km} / \mathrm{h}$ the speed on a turn of $\mathrm{R}=30 \mathrm{~m}$ is in the range of $33.28 \pm 3.43 \mathrm{~km} / \mathrm{h}$, which means the speed is higher by $61.63 \%$. From the resulting dependency formula, it 


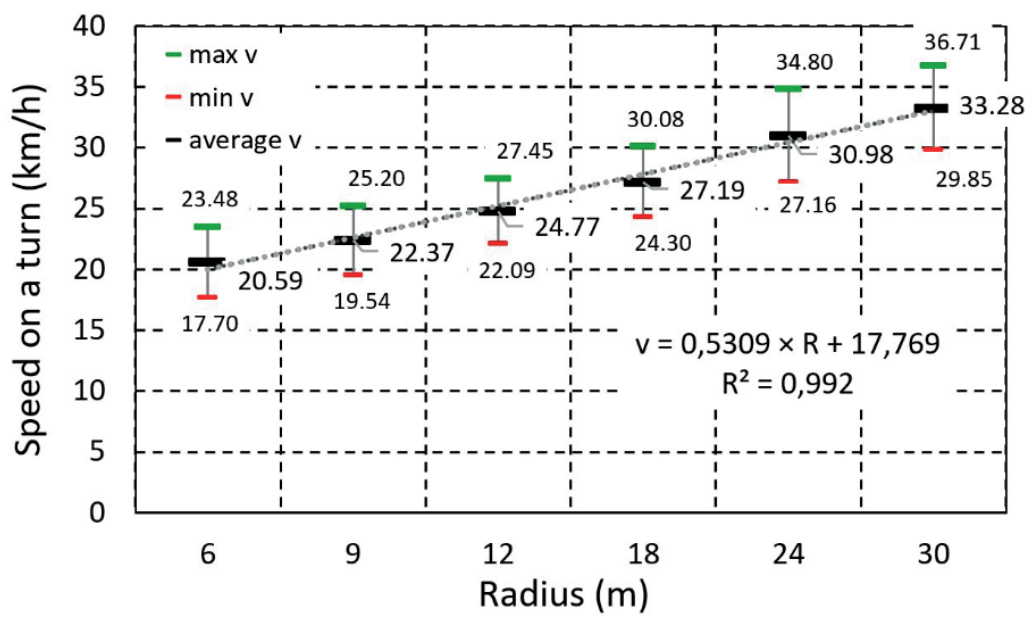

Figure 1 Influence of the right turn radius size on the speed on a turn

Table 3 Through vehicle speed $(\mathrm{km} / \mathrm{h})$ with respect to the right turns for $a=3.4 \mathrm{~m} / \mathrm{s}^{-2}$

\begin{tabular}{ccccccccc}
\hline \multirow{2}{*}{$\mathrm{R}(\mathrm{m})$} & \multicolumn{3}{c}{ Number of right turns } & \multicolumn{5}{c}{ Percentage of right turns } \\
\cline { 2 - 10 } & 25 & 50 & 100 & $10 \%$ & $20 \%$ & $30 \%$ & $40 \%$ & $50 \%$ \\
\hline 6 & 49.033 & 48.729 & 48.096 & 47.318 & 44.459 & 41.754 & 38.245 & 37.128 \\
9 & 49.069 & 48.992 & 48.3 & 47.717 & 46.644 & 44.456 & 42.405 & 38.565 \\
12 & 49.106 & 49.091 & 48.64 & 48.143 & 47.168 & 46.427 & 45.236 & 43.392 \\
18 & 49.135 & 49.176 & 48.903 & 48.37 & 48.145 & 47.594 & 47.073 & 45.856 \\
24 & 49.184 & 49.261 & 49.159 & 49.093 & 49.175 & 48.92 & 48.708 & 48.402 \\
30 & 49.194 & 49.281 & 49.235 & 49.291 & 49.402 & 49.425 & 49.246 & 48.985 \\
\hline
\end{tabular}

Table 4 Reduction coefficient of capacity with respect to the right turns for $a=3.4 \mathrm{~m} / \mathrm{s}^{-2}$

\begin{tabular}{|c|c|c|c|c|c|c|c|c|}
\hline \multirow{2}{*}{$\mathrm{R}(\mathrm{m})$} & \multicolumn{3}{|c|}{ Number of right turns } & \multicolumn{5}{|c|}{ Percentage of right turns } \\
\hline & 25 & 50 & 100 & $10 \%$ & $20 \%$ & $30 \%$ & $40 \%$ & $50 \%$ \\
\hline 6 & 1.00 & 1.00 & 1.00 & 1.00 & 0.99 & 0.98 & 0.96 & 0.94 \\
\hline 9 & 1.00 & 1.00 & 1.00 & 1.00 & 1.00 & 0.99 & 0.97 & 0.96 \\
\hline 12 & 1.00 & 1.00 & 1.00 & 1.00 & 1.00 & 0.99 & 0.98 & 0.98 \\
\hline 18 & 1.00 & 1.00 & 1.00 & 1.00 & 1.00 & 1.00 & 0.99 & 0.99 \\
\hline 24 & 1.00 & 1.00 & 1.00 & 1.00 & 1.00 & 1.00 & 1.00 & 1.00 \\
\hline 30 & 1.00 & 1.00 & 1.00 & 1.00 & 1.00 & 1.00 & 1.00 & 1.00 \\
\hline
\end{tabular}

follows that increasing the turn radius size by $1 \mathrm{~m}$ increases the speed by $0.9 \mathrm{~km} / \mathrm{h}$.

This confirms the assumption that regulations should not quantify all the right turns by one common value because their influence on the vehicle speed might be entirely different.

To determine the influence of selected vehicle maneuvers on decreasing the capacity of collector urban road, a simulation model was developed using the simulation software PTV VISSIM. From geometrical perspective, this was a simple model. To calibrate the model, the final speed values and other characteristics of vehicle movement in traffic flow were used in order to determine the influence of the radius size of the right turns on the capacity of urban road. The microsimulation allows evaluate the traffic flow characteristics second by second based on the new design elements. Software PTV VISSIM could log several indicators (e.g. speed, density and volumes) from the lane segments. The data reflect changes of the traffic flow characteristics depending on design, [16].

Six simulation series were carried out using the model, each one corresponding to a particular radius size and a corresponding speed on a turn (of maximum and minimum size). Thus calibrated, the model was assigned a lane with varying numbers of vehicles going straight and turning right. The alteration of values was carried out 8 times for each series, with the following ratios: 1775:25, 1750:50, 1700:100 vehicles per hour and with the following ratios expressed in percentage: 90:10, 80:20, 70:30, 60:40 and 50:50. The purpose of this variation in ratios of the direction of traffic was to create various situations to determine the influence of the right turn maneuver on the decrease in the capacity of a collector urban road with respect to the number of turning vehicles. The first three ratios corresponded to 


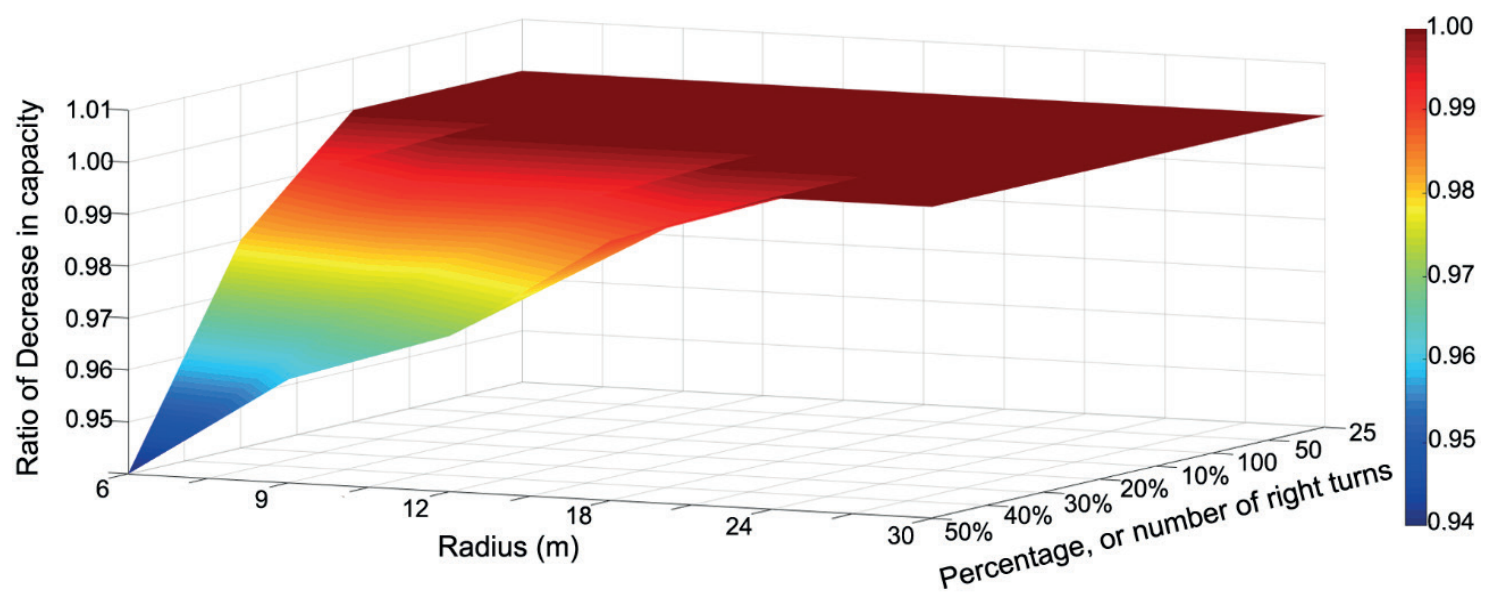

Figure 2 Dependency of decrease of capacity on the number (percentage) of turning vehicles and curve radius size $\left(a=3.4 \mathrm{~m} / \mathrm{s}^{-2}\right)$

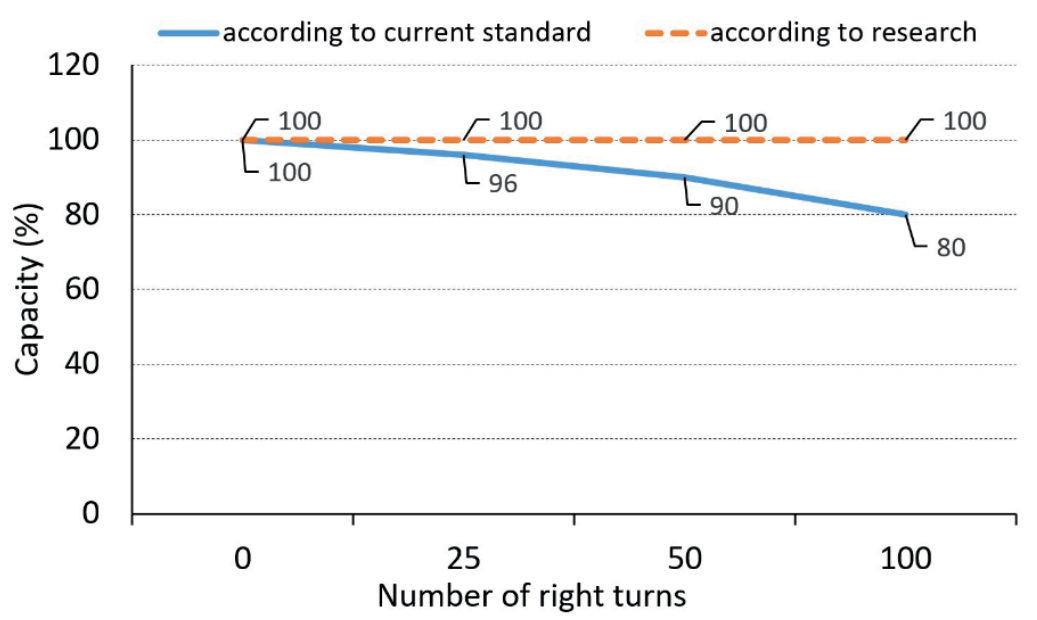

Figure 3 Decrease in capacity with respect to number of the right turns according to the research and according to Slovak standard

the number of turns from the continuous straight lane in direction to the right as they are considered by STN 736110 [17] i.e. 25, 50, 100 maneuvers per hour, respectively. The series were simulated twice, for the value of deceleration of a vehicle of $\mathrm{a}=2.0 \mathrm{~m} / \mathrm{s}^{-2}$ as considered by the simulation software and for the value of deceleration of a vehicle of $\mathrm{a}=3.4 \mathrm{~m} / \mathrm{s}^{-2}$ by AASHTO Green Book [18]. Overall, to determine the influence of the right maneuver on the capacity of the collector urban road, nearly 100 simulations were carried out and evaluated, the required output data being the average speed of the continuous traffic flow and the number of vehicles passing through the model in 1 hour, which was used to determine the decrease of the capacity as a ratio of these vehicles to the number of vehicles equal to the basic capacity, i.e. the basic volume of the collector urban road (reduction coefficient). Examples of results of the simulations are shown in Tables 3 and 4 and Figure 2.

Results show that the decrease in the speed of vehicles in the traffic flow is lower than what was predicted from the absolute values of the speed of vehicles on turn with respect to the radius size. The average decrease in speed of the traffic flow from maximum speed limit was $2.89 \mathrm{~km} / \mathrm{h}$ at $\mathrm{a}=2.0 \mathrm{~m} / \mathrm{s}^{-2}$ and $2.74 \mathrm{~km} / \mathrm{h}$ at $\mathrm{a}=3.4 \mathrm{~m} / \mathrm{s}^{-2}$. Considering the fact that the initial required speed of vehicles in a simulation model oscillates within the range $50 \pm 2.0 \mathrm{~km} / \mathrm{h}$, the decrease in the speed of the through traffic flow due to the right turn is very low. Maximum decrease in speed is 13 $\mathrm{km} / \mathrm{h}$, which corresponds to the minimum radius size and represents $50 \%$ of the right turns.

The results show that the deceleration of vehicles prior to turning (i.e. the distance from the edge of the intersection at the moment when deceleration began) does not have a significant influence on the traffic flow as a whole and the corresponding average decrease in speed and urban road capacity.

From these findings follows that influence of the right turn on the decrease in the capacity of urban road is not significant. Decrease in capacity takes place when the ratio of turning vehicles is high ( $30 \%$ and more), provided that the radius size is lower than $12 \mathrm{~m}$. Table 4 illustrate that maximum decrease of capacity according to the reduction coefficient determined from the ratio of vehicles released by the simulation model to the initial number of vehicles, is approximately $6 \%$, at minimum radius size and $50 \%$ of right turns. 


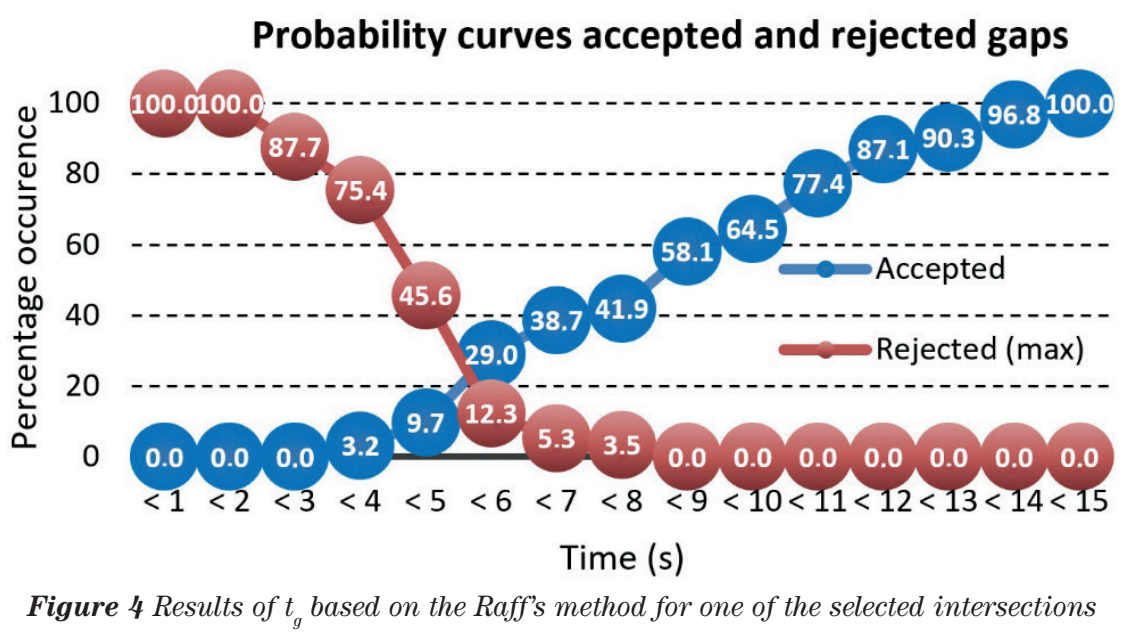

Based on the findings, it is possible to determine functional levels for the quality assessment of the collector urban roads according to speed.

Comparison to the methods of assessment of the right turns according to Slovak standard [17] shows that when the number of turns is 25 , the capacity of the section decreases by $4 \%$; with the number of turns being 50 , there will be a $10 \%$ decrease; and with 100 turns, the expected decrease is $20 \%$. Research results for such a number of turning vehicles did not shown any decrease in capacity (Figure 3).

\subsection{Left turns}

The effect of the left turns to the decreasing of the capacity of simple intersections is determined in the Slovak Standard without the influence of opposite traffic flow intensity. For the purpose of determining the influence of the left turn on decrease in capacity, measurements were carried out at 5 uncontrolled intersections in the city of Zilina. Measurements were performed at individual spots in duration of 4 hours in order to record the traffic flow during the peak hour, as well as in lower volumes.

To determine the influence of the left turn on the capacity of urban road it was necessary to first determine the critical gap. For this purpose, the Raff's method was used, which draws values of the critical time gap from the intersection of sum lines of accepted and rejected gaps (Figure 4). The sum line for accepted gaps (the rising curve) is a line, whose every point states the percentage of all the accepted gaps that are lower than the given gap. The sum line for rejected gaps (the declining curve) is a line, whose every point state what percentage of all the rejected gaps is greater than the given gap. For every vehicle, only its maximum rejected gap was considered for the sum line (a vehicle may reject more gaps for turns on the superior counter flow in the traffic flow). For the evaluation purpose, were considered only gaps of those drivers who, prior to accepting a gap in the superior traffic flow to make a left turn, had rejected at least one gap and at the same time, did not accept a gap that was lower than the one they had rejected before.

The outcome of the measurements, processed videos from individual intersections and subsequently obtained accepted and maximum rejected gaps, was an estimation of critical time gaps. They were determined for individual intersections, which were observed by four selected methods of assessment:

1. estimate of $t_{g}$ based on the gaps that were accepted and rejected by drivers turning left, and which occurred between the two vehicles driving only straight in a superior traffic flow during the peak-hour intensity label (PHI without RT)

2. estimate of $t_{g}$ based on all the gaps that were accepted and created by drivers turning left, which occurred in a superior traffic flow during the peak-hour intensity label (PHI)

3. estimate of $t_{g}$ based on the gaps that were accepted and rejected by drivers turning left, and occurred between the two vehicles driving only straight in a superior traffic flow during the time of measurements - label (all measurements, without RT)

4. estimate of $t_{g}$ based on the gaps that were accepted and rejected by drivers turning left, and which occurred in a superior traffic flow during the time of measurements - label (all measurements).

The results of these evaluations are presented in Table 5 .

The results show a relatively broad span in $t_{g}$, which is dependent on the type and quantity of data it was estimated from. The $t_{g}$ based on measurements taken during the peak hour has a larger span than $t_{g}$ based on all the measurements, taken during the entire observation. The maximum span of $t_{g}$ reaching 2.0 seconds resulted from evaluation of gaps between the two vehicles driving straight in the superior traffic, which drivers turning left accepted or rejected during the peak hour. The dependency of the critical time gaps $t_{g}$ on the intensity of superior streams is illustrated by Figure 5 . 
Table 5 Span of the critical time gaps $t$ obtained from evaluations of accepted and maximum rejected gaps

\begin{tabular}{|c|c|c|c|}
\hline \multicolumn{4}{|l|}{$\mathrm{t}_{\mathrm{g}}(\mathrm{s})$} \\
\hline University of Zilina Research (PHI) & 5.0 & - & 6.0 \\
\hline University of Zilina Research (PHI, without Right Turns) & 4.0 & - & 6.0 \\
\hline University of Zilina Research (all measurements) & 5.1 & - & 5.7 \\
\hline University of Zilina Research (all measurements, without Right Turns) & 5.1 & - & 5.7 \\
\hline
\end{tabular}

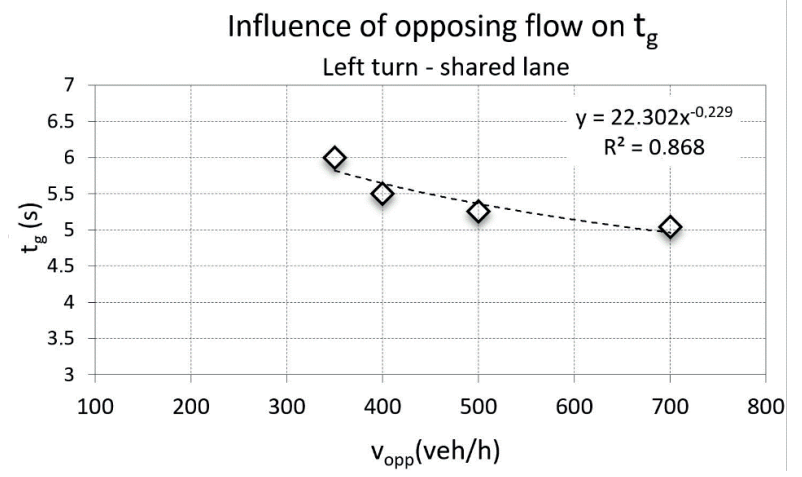

Figure 5 Dependency of $t_{a}$ on the intensity of the superior traffic stream

Analyzed measurements confirm the dependency of the critical time gaps $t_{g}$ on the intensity of vehicles in the superior traffic flow. With rising intensity, drivers turning left accept shorter gaps between vehicles. This phenomenon has been confirmed by the results of research done in [19], [20], [21]. Figure 6 presents the results of studies of Czech Technical University [21] and University of Zilina. The comparison was chosen on the dependence of very similar traffic conditions in Czech and Slovak republic.

The speed of decrease of $t_{g}$ (the steepness of the curve) is lower in the case of results obtained by authors than in the case of dependency discovered by the study by Czech Technical University (CVUT). This may result from factors such as the speed of the superior traffic flow as well as the mentality of drivers. While the dependency obtained from the CVUT study is represented by a linear function, the dependency obtained from authors is represented by an exponential function, which better describes the trend in data (the authors-expect that with rising intensity of superior streams the value of $t_{g}$ will be stable, i.e. it will never equal to zero). The results have been confirmed also by [22], where the observed $t_{g}$ value was 5.8-6.04 s. In order to determine the influence of the left turn maneuvers of vehicles on capacity of the collector urban road, 4 series of simulations were carried out in a simulation model. In each series, different value of the critical time gap ( $4.0 \mathrm{~s}$ - minimum; $5.3 \mathrm{~s}$ - average; $5.5 \mathrm{~s}$ - stated in the Slovak Technical Condition TP 102 [23]); $6.0 \mathrm{~s}$ - maximum) was entered for the link, from which vehicles turned left from the main road to a side street. Direction of the traffic varied at the point of entry into this link, from entry in the straight direction and to the left in a similar fashion as in the case of the right turn in various ratios. Three ratios corresponded to the number of the left turns from the continuous traffic flow to the left in a way that is considered by Slovak

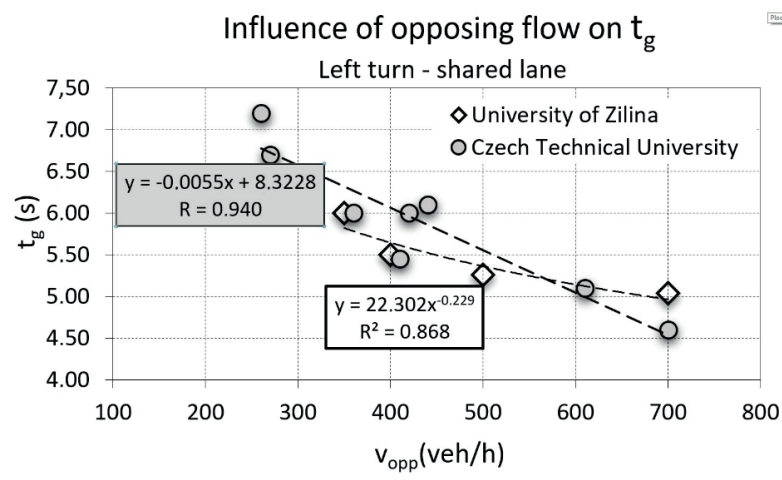

Figure 6 Dependency of $t_{g}$ on the intensity of superior traffic stream - comparison of author's study (trend described by exponential function) and the CVUT study, [21]

standard [17]). Since it is expected that the capacity of a section of a collector urban road in the case of the left turns is largely influenced by the density of the superior traffic flow, the entry intensity values for the superior stream in the simulation model varied from 100 to 1800 . Overall, to determine the influence of the left maneuver on decrease in the capacity of the collector urban road, 576 simulations were carried out and evaluated leading to 576 reduction coefficients. An example of the simulation results is presented by Figures 7 and 8 .

From the findings follows that with increasing critical time gap $t_{g}$ increases the influence of left turn, which causes a significant decrease in the capacity of a section. With the maximum number of turns ( $100=33$ left turns $)$, which is considered by Slovak Standard [17], the decrease in capacity may be as much as $39 \%$ (entry volume $1800 \mathrm{pc} / \mathrm{h}$ with the number of vehicles in the superior traffic flow 1800 $\mathrm{pc} / \mathrm{h}$ ), or $43 \%$ (entry volume $1233 \mathrm{pc} / \mathrm{h}$ with the number of vehicles in the superior traffic flow $1800 \mathrm{pc} / \mathrm{h}$ ).

With the maximum number of turning vehicles, as it is considered by the standard, and with the volume upon entry at $1800 \mathrm{pc} / \mathrm{h}$, the capacity does not decrease until the number of turning vehicles in the superior traffic flow reaches $1500 \mathrm{pc} / \mathrm{h}$ at $t_{g}=4 \mathrm{~s}$. With other $\mathrm{t}_{\mathrm{g}}$ the decrease does not manifest until the intensity of the superior traffic flow is equal to $1233 \mathrm{pc} / \mathrm{h}$.

Increase in the number of turning vehicles causes increase in the influence of the left turn, which results in a significant decrease in the capacity of a section. At the ratio of the left turning vehicles of $10 \%$, the capacity decreases as soon as the volume of the superior traffic stream is $700 \mathrm{pc} / \mathrm{h}$, with $t_{q}=4 \mathrm{~s}$ leading to a decrease by $6 \%$, and with $t_{g}=6 \mathrm{~s}$ up to $14 \%$ (at the intensity upon entry at 1800 pc/h) (Figure 9). 


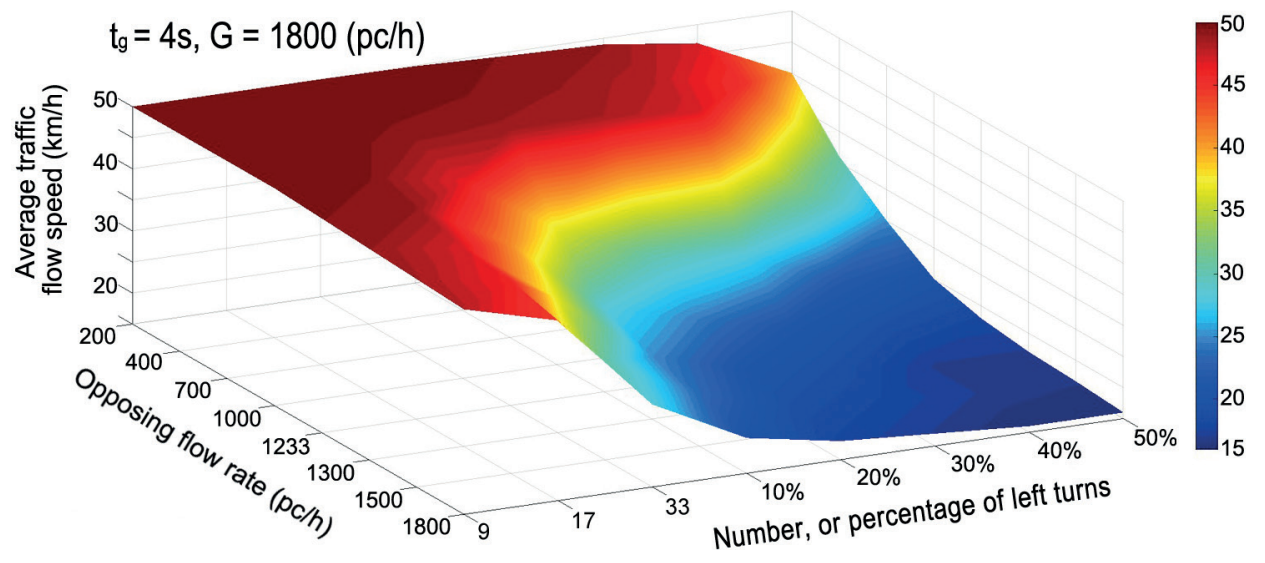

Figure 7 Dependency of average speed of the traffic stream on the number (percentage) of turning vehicles and the intensity of counter-stream DP

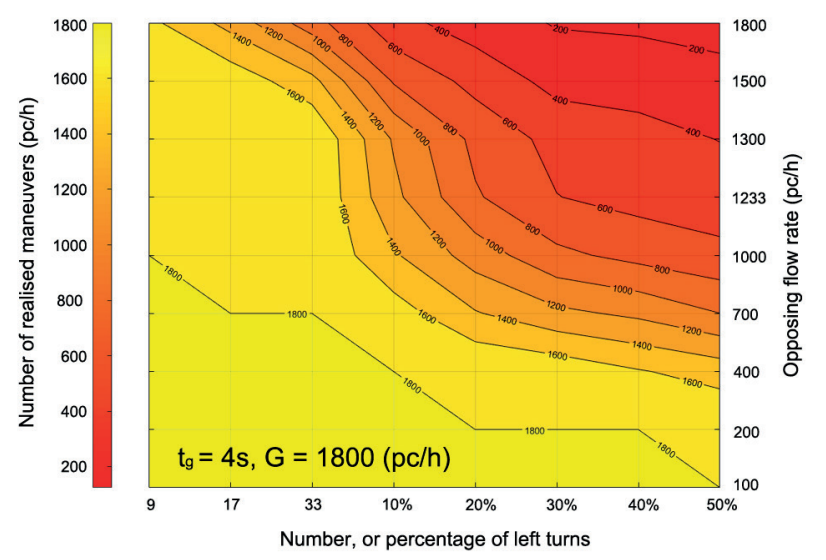

Figure 8 Dependency of number of realized maneuvers on the number (percentage) of turning vehicles and the opposing flow rate

\section{Opposing flow rate $700 \mathrm{pc} / \mathrm{h}, 10 \%$ left turning}

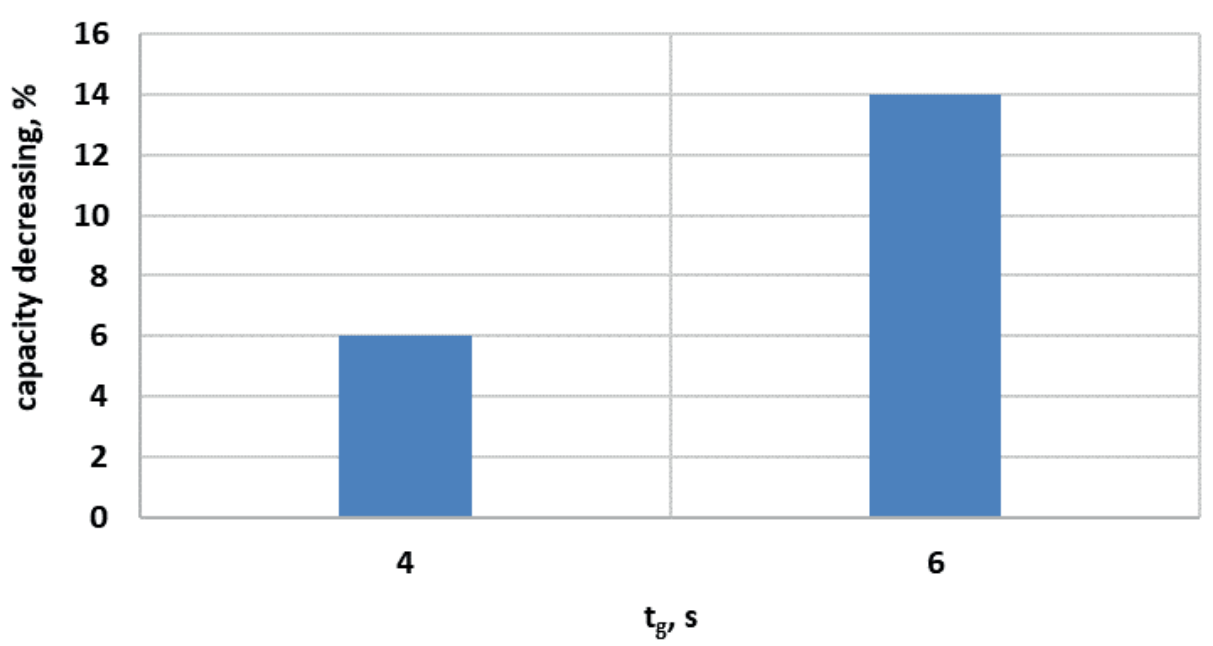

Figure 9 Dependency of capacity decreasing on the $t_{q}$ value

Given the same volume upon entry and the ratio of turning vehicles being $50 \%$, the capacity decreases as soon as the intensity of the superior traffic stream is at $400 \mathrm{pc} / \mathrm{h}$, at $t_{g}=4$ or $200 \mathrm{pc} / \mathrm{h}$ for other $t_{g}$.
For 33 left turns, the standard considers flat decrease in the capacity by $20 \%$ with no regard to the intensity of the superior traffic flow and the critical time gap. The research findings show that decrease in the capacity spans between $0-28 \%$ for $t_{g}=4.0 \mathrm{~s} ; 0-53 \%$ for $t_{g}=5.3 \mathrm{~s} ; 0-71 \%$ for $t_{g}=5.5$ 
$\mathrm{s}$ and $6.0 \mathrm{~s}$. From that follows that the capacity of a section should not be determined solely by the number of the left turns because of the broad span of the rate of influence of this maneuver in relation to the intensity of the superior traffic flow. In the extreme case, a higher ratio of the left turns may decrease the capacity by as much as $90 \%$.

\section{Conclusion}

The analysis of results shows that the right turn per se does not significantly influence the decrease in the capacity of urban road as it is considered by the Slovak standard [17]. The decrease in the capacity only occurs at a high ratio of turning vehicles (min. 30\%) and at the radius size not being larger than $12 \mathrm{~m}$. From that follows that in order to assess the capacity of urban road, it would be more objective to use a combination of the two methods - to determine Level of Service (LOS) based on the speed of the continuous traffic flow and decrease in the capacity based on the reduction coefficient.

In the case of the left turn, the results show clear dependency of the capacity of urban road and the speed of traffic flow on the combination of the intensity, i.e. the ratio of turning vehicles and volume of the superior traffic flow.

All the obtained dependencies could provide guidelines for the assessment of collector roads not based on the decreasing their capacity but based on determination of functional levels with respect to the average speed of vehicles in traffic flow, as well. It has clearly been shown that besides the number of turning vehicles, it is necessary to take into account other characteristics of the traffic flow, such as the intensity of the superior traffic stream and the critical time gap. The presented results objectify and expand the scale of values required for the determination of the maneuvering coefficient.

Furthermore, in order to determine the decrease in the capacity of uncontrolled intersections in the urban areas [24], it is necessary to pay attention to impact of pedestrians on the turning maneuvers and also the effect of intersections with the unconventional arrangement of superior traffic flows. In this respect, research activities at the university are already being implemented and are directed towards adjusting the Slovak standards and technical regulations.

\section{References}

[1] KIM, J-T. Estimation of uniform delay of permitted left turns from exclusive turn lanes. Journal of Transportation Engineering [online]. 2006, 132(9), p. 708-714. ISSN 0733-947X, eISSN 1943-5436. Available from: https://doi.org/10.1061/(ASCE)0733-947X(2006)132:9(708)

[2] TROUTBECK, R. J., BRILON, W. Unsignalized intersections theory [online]. 1997. Available from: https://www.fhwa.dot.gov/publications/research/operations/tft/chap8.pdf

[3] KIM, J., ELEFTERIADOU, L. Estimation of capacity of two-lane two-way highways using simulation model. Journal of Transportation Engineering [online]. 2010, 136(1), p. 61-66. ISSN 0733-947X, eISSN 1943-5436. Available from: https://doi.org/10.1061/(ASCE)0733-947X(2010)136:1(61)

[4] CHANDRA, S., AGRAWAL, A., RAJAMMA, A. Microscopic analysis of service delay at uncontrolled intersections in mixed traffic conditions. Journal of Transportation Engineering [online]. 2009, 135(6), p. 323-329. ISSN 0733-947X, eISSN 1943-5436. Available from: https://doi.org/10.1061/(ASCE)0733-947X(2009)135:6(323)

[5] HUBBARD, S. M. L., BULlOCK, D. M., MANNERING, F. L. Right turns on green and pedestrian level of service: statistical assessment. Journal of Transportation Engineering [online]. 2009, 135(4), p. 153-159. ISSN 0733-947X, eISSN 1943-5436. Available from: https://doi.org/10.1061/(ASCE)0733-947X(2009)135:4(153)

[6] OGALLO, H. O., JHA, M. K. Methodology for critical-gap analysis at intersections with unprotected opposing left-turn movements. Journal of Transportation Engineering [online]. 2014, 140(9), p. 1-7. ISSN 1757-8981, eISSN 1757-899X. Available from: https://doi.org/10.1061/(ASCE)TE.1943-5436.0000691

[7] XIAO, Y., RAN, Q., YANG, J., WANG, Z. Analysis and Modeling of Crossing Behavior at Urban Intersections in China. Journal of Transportation Engineering [online]. 2011, 137(2), p. 121-127. ISSN 1757-8981, eISSN 1757-899X. Available from: https://doi.org/10.1061/(ASCE)TE.1943-5436.0000201

[8] LIU, P., LU, J. J., HU, F., SOKOLOW, G. Capacity of U-turn movement at median openings on multilane highways. Journal of Transportation Engineering [online]. 2008, 134(4), p. 147-154. ISSN 0733-947X, eISSN 1943-5436. Available from: https://doi.org/10.1061/(ASCE)0733-947X(2008)134:4(147)

[9] LIU, P., QU, X., YU, H., WANG, W., CAO, B. Development of a VISSIM simulation model for U-turns at unsignalized intersections. Journal of Transportation Engineering [online]. 2012, 138(11), p. 1333-1339. ISSN 1757-8981, eISSN 1757-899X. Available from: https://doi.org/10.1061/(ASCE)TE.1943-5436.0000438

[10] TRB Transportation Research Board of the National Academies. HCM2010 - Highway Capacity Manual. Vol. 3: Interrupted flow. USA: National Academy of Sciences, 2010. ISBN 0-309-06681-6.

[11] FITZPATRICK, K., SCHNEIDER IV., W. H., PARK, E. S. Predicting speeds in an urban right-turn lane. Journal of Transportation Engineering [online]. 2006, 132(3), p. 199-204. ISSN 0733-947X, eISSN 1943-5436. Available from: https://doi.org/10.1061/(ASCE)0733-947X(2006)132:3(199) 
[12] CHICK, C. On-street parking - A guide to practice. London: Landor Publishing, 1996. ISBN 1899650-01-6.

[13] VALLELEY, M. Parking perspectives: A source book for the development of parking policy. London: Landor Publishing, 1997. ISBN 1-899650-06-7.

[14] YOUSIF, S., PURNAWAN, S. On-street parking: Effects on traffic congestion. Traffic Engineering \& Control. 1999, 40(9), p. 424-427. ISSN 0041-0683.

[15] GUO, H., GAO, Z., YANG, X., ZHAO, X., WANG, W. Modeling travel time under the influence of on-street parking. Journal of Transportation Engineering [online]. 2012, 138(2), p. 229-235. ISSN 0733-947X, eISSN 1943-5436. Available from: https://doi.org/10.1061/(ASCE)TE.1943-5436.0000319

[16] KOCIANOVA, A, DRLICIAK, M., PITLOVA, E. Influence of roundabout capacity enhancement on emission production. IOP Conference Series: Materials Science and Engineering [online]. 2017, 236, art. no. 012035. ISSN 1757-8981, eISSN 1757-899X. Available from: https://doi.org/10.1088/1757-899X/236/1/012035

[17] STN 736110 Projektovanie miestnych komunikacii / Design of the urban streets (in Slovak). Slovak Technical Standard. Bratislava: SUTN, 2004.

[18] AASHTO Green Book. A policy on geometric design of highways and streets. Washington, DC: American Association of State Highway \& Transport, 2001. ISBN 1560511567.

[19] AKCELIK, R. A review of gap-acceptance capacity models. 29th Conference of Australian Institutes of Transport Research CAITR 2007: proceedings. 2007.

[20] GUO, R. J., WANG, X. J., WANG, W. X. Estimation of critical gap based on Raff's definition. Comput Intell Neurosci [online]. 2014, 236072. ISSN 1687-5265, eISSN 1687-5273. Available from: https://doi.org/10.1155/2014/236072

[21] SLABY, P. Faktory ovlivnujici kapacitu nerizene krizovatky /Factors determinated of the unsignalised intersection capacity (in Czech). Silnicni obzor. 2007, 1, p. 16-17. ISSN 0322-7154.

[22] GAVUlOVA, A. Use of statistical techniques for critical gaps estimation. 12th International Conference RelStat'12: proceedings. CD ISBN 978-9984-818-49-8, p. 20-26.

[23] TP 102. Vypocet kapacit pozemnych komunikacii / Capacity analysis of the roads. Slovak Technical Condition. Ministry of Transport, Construction and Regional Development of Slovak Republic 2015 (in Slovak).

[24] HUSZAROVA, K. Kapacitne vypocty miestnych komunikacii / Capacity analysis of the urban streets (in Slovak). Ph.D. thesis. Zilina: University of Zilina, 2012. 